\title{
Pulmonary Neuroendocrine Tumor with Thyroid Gland Metastasis: Case Report
}

\section{Cristina Corina Pop Radu*}

Department of endocrinology, University of Medicine and Pharmacy Târgu Mureș, Romania

\begin{abstract}
Neuroendocrine tumors (NET) represent approximately $20 \%$ of all primary neoplasms of the lung. Histologic confirmation is important for treatment and prognosis determination. NET are classified according to four subtypes in the lung: typical carcinoid tumor (TC), atypical carcinoid tumor (AC), small cell carcinoma (SCC), and large cell neuroendocrine carcinoma (LCNEC). TC is low-grade, AC is intermediate-grade, and SCC and LCNEC are high-grade malignancies.

Case report: A 57 years old woman, affected by a cervical anterior tumor and a proliferative tissue below the glottis was referred to our Endocrinology Department from ENT service for a second opinion. An ultrasound scan of the neck showed a polynodular goiter with bilaterally lymph nodes enlargement with suspicious malignancy characters. She had undergone surgery for the cervical anterior mass and for the laryngeal biopsy. Histopathological examination results were consistent with a SCC; neoplastic cells showed immunoreactivity to synaptophysin, neuron specific enolase and chromogranin. The serum levels of serotonin, cromogranin A, calcitonin, carcinoembryonic antigen, ACTH, PTH, TSH, FT4 were normal. Fine needle aspiration biopsy of her left thyroid lobe nodule was performed and the cytopathological exam was compatible with a neuroendocrine tumor metastasis. Thoracic and abdominal computed tomography was normal at that moment. Chest CT revealed the primary pulmonary tumor at 6 months after presentation. The therapeutic option for advanced or metastatic NETs is mainly palliation of symptoms; options need to be individualized and, therefore, rely on the knowledge of multidisciplinary teams.
\end{abstract}

Keywords: Pulmonary neuroendocrine tumor; Small cell lung carcinoma; Thyroid metastasis

\section{Introducere}

Tumorile pulmonare neuroendocrine (TPNE) reprezintă aproximativ $20 \%$ dintre toate tumorile primare ale plămânilor. Confirmarea histologică este importantă pentru tratament și determinarea prognosticului. În 2004, OMS a introdus sistemul de clasificare histologică a tumorilor anterior clasificate împreună drept „carcinoide” pulmonare. Acest sistem cuprinde patru subtipuri: tumori carcinoide tipice $(\mathrm{CT})$ - cu grad mic de malignitate, tumori carcinoide atipice (CA) - cu grad intermediar, carcinomul cu celule mici $(\mathrm{CNECm})$ și carcinomul cu celule mari (CNECM), ultimele două cu grad înalt de malignitate. CT și CA sunt clasificate împreună ca și „Carcinoide”, CNECM este considerat un subgrup, iar CNECm este o categorie independentă (Tabel I) [1].

Deși tiroida are o vascularizație bogată, metastazele de tumori solide în tiroidă sunt raportate rar $(1,4 \%)$. Incidența acestora stabilită clinic este mai mică de $1 \%$, dar studii pe atopsii seriate au evidențiat faptul că metastazarea în tiroidă a apărut pâna la $24 \%$ dintre pacienții care au decedat prin cancer [2]. Leziunile tiroidiene metastatice sunt datorate în majoritatea cazurilor carcinoamelor de sân, plămân, stomac, esofag, renal și melanomului [2,3]. Cele mai frecvente tipuri histologice de cancer pulmonar raportate cu metastazare în tiroidă sunt adenocarcinomul și carcinomul cu celule squamoase, urmate de CNECM. CNECm care reprezintă 15-20\% dintre TPNE metastazează rar în tiroidă, în literatură fiind raportate cazuri izolate [3].

\section{Prezentare de caz}

Prezentăm cazul unei paciente în vârstă de 57 de ani care a fost internată în Clinica de Endocrinologie în 2009 pentru investigarea unei guși polinodulare însoțită de adenopatii latero-cervicale bilaterale, fiind trimisă din serviciul ORL. Laringoscopia directă efectuată în serviciul ORL a evidențiat țesut proliferativ subglotic. Principalele acuzele subiective au fost: disfonie intermitentă, tuse și dispnee la eforturi medii. Examenul obiectiv endocrin: IMC - 29,8 kg/m2, curbă ponderală constantă, gușă polinodulară, cu consistență crescută, mobilă la deglutiție, nedureroasă, cu multiple adenopatii laterocervicale și supraclaviculare bilateral în conglomerat, ferme, aderente, imobile, nedureroase. Superior de glanda tiroidă, prelaringian formațiune tumorală de aproximativ $2 / 1,5 \mathrm{~cm}$, fermă, mobilă. Fără alte modificări clinice obiective. Tensiune arterială $-120 / 75 \mathrm{mmHg}$, AV- 72/minut. Fără sindrom tumoral hipofizar și fără semne clinice de disfuncții endocrine, menopauza la 39 de ani, examenul senologic - fără formațiuni nodulare la palpare și fără secreție la exprimarea mameloanelor.

Ecografia regiunii cervicale anterioare (Figura 1) a confirmat prezența unei guși polinodulare însoțită de multiple adenopatii latero-cervicale și supraclaviculare bilateral cu caractere suspecte de malignitate. În regiunea cervicală anterioară, superior de glanda tiroidă conglomerat nodular hipoecogen, inomogen cu vascularizație peri- și intranodulară de $25 / 10 \mathrm{~mm}$. S-a intervenit chirurgical în serviciul ORL pentru extirparea formațiunii prelaringiene și s-a efectuat biopsie din țesutul proliferativ subglotic.

*Corresponding author: Cristina Corina Pop Radu MD, Medic Primar Endocrinolog, Department of Endocrinology, University of Medicine and Pharmacy Târgu Mures, Gheorghe Marinescu Street, No 38540139, Târgu Mures, Romania, Tel: +40 (0) 265214410 / 236; E-mail: ccorinaradu@yahoo.com

Received October 11, 2014; Accepted November 14, 2014; Published November 20,2014

Citation: Pop Radu C. [Pulmonary Neuroendocrine Tumor with Thyroid Gland Metastasis: Case Report]. Journal of Surgery [Jurnalul de chirurgie] 2015; 10(4): 287-290 DOI:10.7438/1584-9341-10-4-9 [article in Romanian]

Copyright: (c) 2015 Pop Radu C. This is an open-access article distributed under the terms of the Creative Commons Attribution License, which permits unrestricted use, distribution, and reproduction in any medium, provided the original author and source are credited. 
Tabel I: Clasificarea Histologică a TPNE [1].

\begin{tabular}{|c|c|c|c|}
\hline Tipul tumorii & Aspecte histologice & Imunohistochimie & Grad de malignitate \\
\hline CT & Arhitectură carcinoidă; < 2 mitoze/10HPF & Cg A; SNF; ENS; RS & Grad 1; scăzut \\
\hline CA & Arhitectură carcinoidă; 2-10 mitoze/10HPF; necroză focală & Cg A; SNF; ENS; RS & Grad 2; intermediar \\
\hline CNECM & $\begin{array}{l}\text { Morfologie neuroendocrină (rozete organoide, cuiburi palisade, trabecule); celule mari cu raport } \\
\text { nucleu/citoplasmă scăzut, cromatină veziculară sau fină; necroză }\end{array}$ & $\begin{array}{l}\text { Expresie slabă a SNF și a ENS; } \\
\text { mutații ale genei p } 53\end{array}$ & Grad 3; mare \\
\hline CNECm & $\begin{array}{l}\text { Dimensiuni mici; citoplasmă insuficientă; nucleu cu cromatină fin-granulară, nucleol absent sau } \\
\text { vag conturat }\end{array}$ & $\begin{array}{l}\text { Expresie slabă a SNF și a ENS; } \\
\text { mutații ale genei p } 53\end{array}$ & Grad 3; mare \\
\hline
\end{tabular}

CT carcinod tipic; CA carcinoid atipic; CNECM carcinom neuroendocrin cu celule mari; CNECm carcinom neuroendocrin cu celule mici; CgA cromogranina A; SNF sinaptofizina; ENS enolaza neuron-specifică; RS receptori la somatostatină; HPF high-power field.
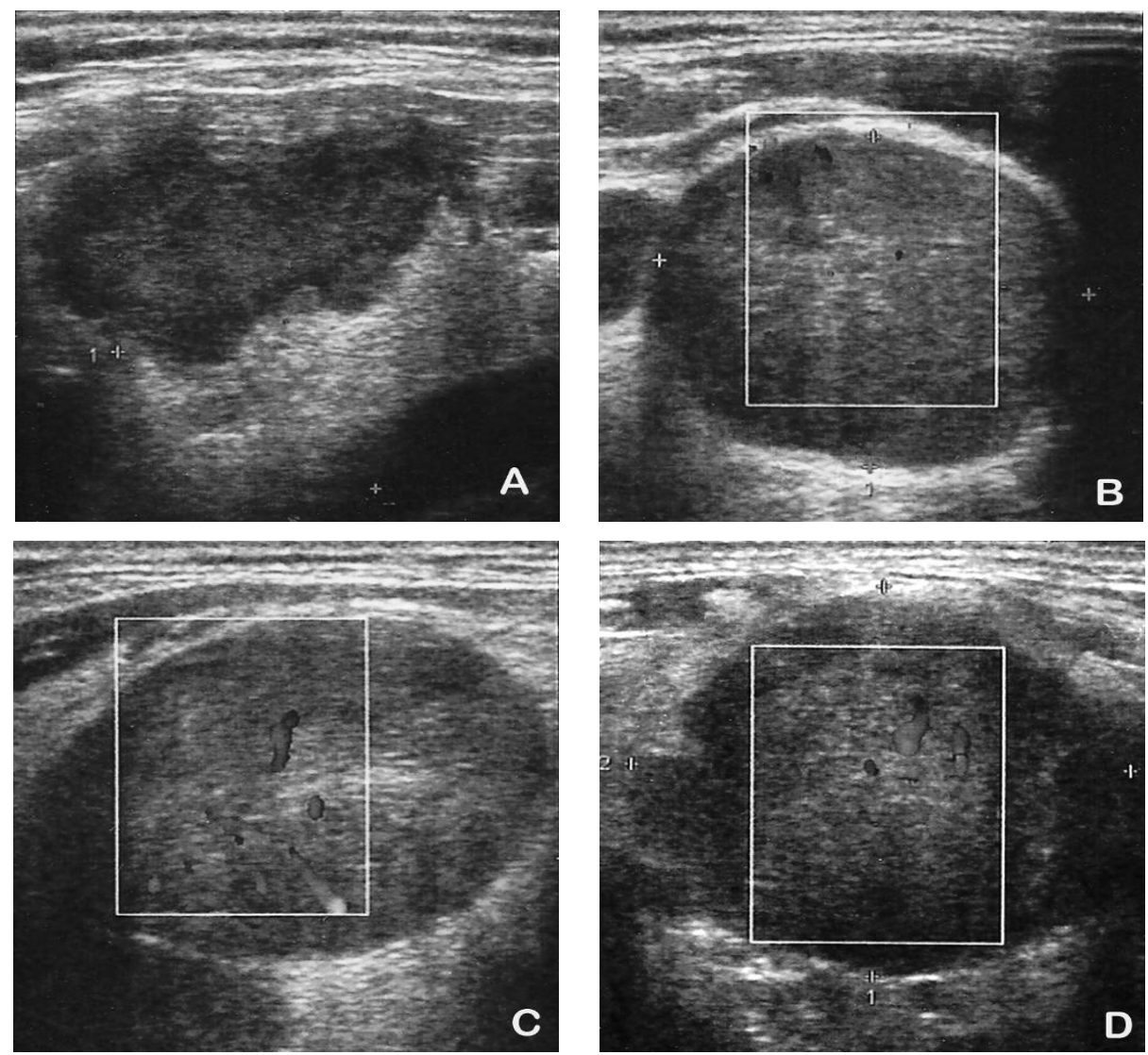

Figura 1: Ecografia tiroidiană A) Lob tiroidian stâng: anterior și inferior - macronodul cu dimensiuni de 27x14,4 mm, hipoecogen, inomogen, cu margini neregulate ș vascularizatie intranodulara intensă la examinarea color flow-Doppler, ce invadează capsula anterioară. B, C, D) bilateral multiple formațiuni nodulare latero-cervicale și supraclaviculare hipoecogene, inomogene, cu vascularizație intranodulară, cu dimensiuni de $28,6 \times 25,3 \mathrm{~mm}$.

Examenul histopatologic (laringe și nodul limfatic) a evidențiat carcinom cu celule mici de tip neuroendocrin (celule cu citoplasma redusă, nuclei rotunzi-ovalari, fără nucleoli vizibili, cu atipie citonucleară marcată, dispuse în placarde sau trabecule, uneori cu formare de rozete), cu imunohistochimie pozitivă pentru sinaptofizină, enolaza neuron specifica (ENS) și focal pozitivă pentru cromogranină. Nivelele serice de $\mathrm{CgA}$, serotonină, calcitonină, antigen carcinoembrionar (ACE), corticotropină (ACTH), parathormon $(\mathrm{PTH})$, tireotropină (TSH), tiroxină liberă (FT4), prolactină (PRL) au fost normale. Acidul 5 hidroxi-indol-acetic urinar (5 HIAA) a fost de asemenea în limite normale (Tabel II).

Examenul citopatologic al puncției tiroidiane cu ac fin a confirmat prezența carcinomului neuroendocrin cu celule mici la nivelul tiroidei (Figura 2 A-D).

Computer tomografia cervico-toraco-abdominală a evidențiat îngroșarea marcată a mucoasei peretelui posterior al traheeei în regiunea incipientă cu reducerea lumenului la jumătate. Multiple adenopatii supraclaviculare și latero-cervicale bilaterale cu dimensiuni până la $25 \mathrm{~mm}$, în rest aspect pulmonar și abdominal normal. Examenul cardiologic cu ecocardiografie a diagnosticat o cardiopatie ischemică cronică cu angină pectorală de efort și minimă colecție pericardică. Radiografia de șa turcească: șa cu dimensiuni normale, $\mathrm{cu}$ contur inferior dublu și fin neregulat, $\mathrm{cu}$ osteoporoza dorsului selar și infraselar; calcificări supraselare de $8 / 5 \mathrm{~mm}$. Pacienta a fost remisă serviciului de oncologie pentru efectuarea tratamentului de specialitate chimioterapie- radioterapie. Tumora primară pulmonară a fost vizualizată la 6 luni de la diagnosticul metastazelor tiroidiene prin examen computer tomografic toracic. Decesul a survenit la 1 an de la diagnostic.

\section{Discuții}

CNECm reprezintă 15-20\% dintre TPNE. În ultimii ani incidența globală a CNECm a fost în scădere, datorită renunțării la fumat, dar s-a observat pe de altă parte o creștere a acesteia la sexul feminin, cu un raport pe sexe de 1:1. Prezintă mai multe subtipuri histologice și este adesea însoțit de activitate neuroendocrină [1]. Localizat cel mai adesea central, în $80 \%$ din cazuri prezintă metastaze în momentul stabilirii 
Tabel II: Markeri tumorali și dozări hormonale.

\begin{tabular}{|c|c|c|c|}
\hline Parametru & Rezultat & Interval de referinţă & $19-98$ \\
\hline Cromogranina A & 37 & $117-190$ \\
\hline Serotonina & 68,9 & $<13$ \\
\hline Calcitonina & 4,22 & \multicolumn{2}{|c|}{ Unitate de măsură } \\
\hline ACE & 1,2 & $\mathrm{pg} / \mathrm{ml}$ \\
\hline ACTH & 20 & $\mathrm{ng} / \mathrm{ml}$ \\
\hline PTH & 46 & $\mathrm{pg} / \mathrm{ml}$ \\
\hline TSH & 1,89 & $\mathrm{Jg} / \mathrm{ml}$ \\
\hline FT4 & 1,3 & $0,4-3,45$ \\
\hline PRL & 23 & $0,8-1,7$ \\
\hline 5 HIAA & 4,3 & $2,39-25$ \\
\hline
\end{tabular}

ACE antigen carcinoembrionar; ACTH corticotropina; PTH parathormon; TSH tireotropina; FT4 tiroxina liberă; PRL prolactina; 5 HIAA acidul 5 hidroxi-indol-acetic urinar.
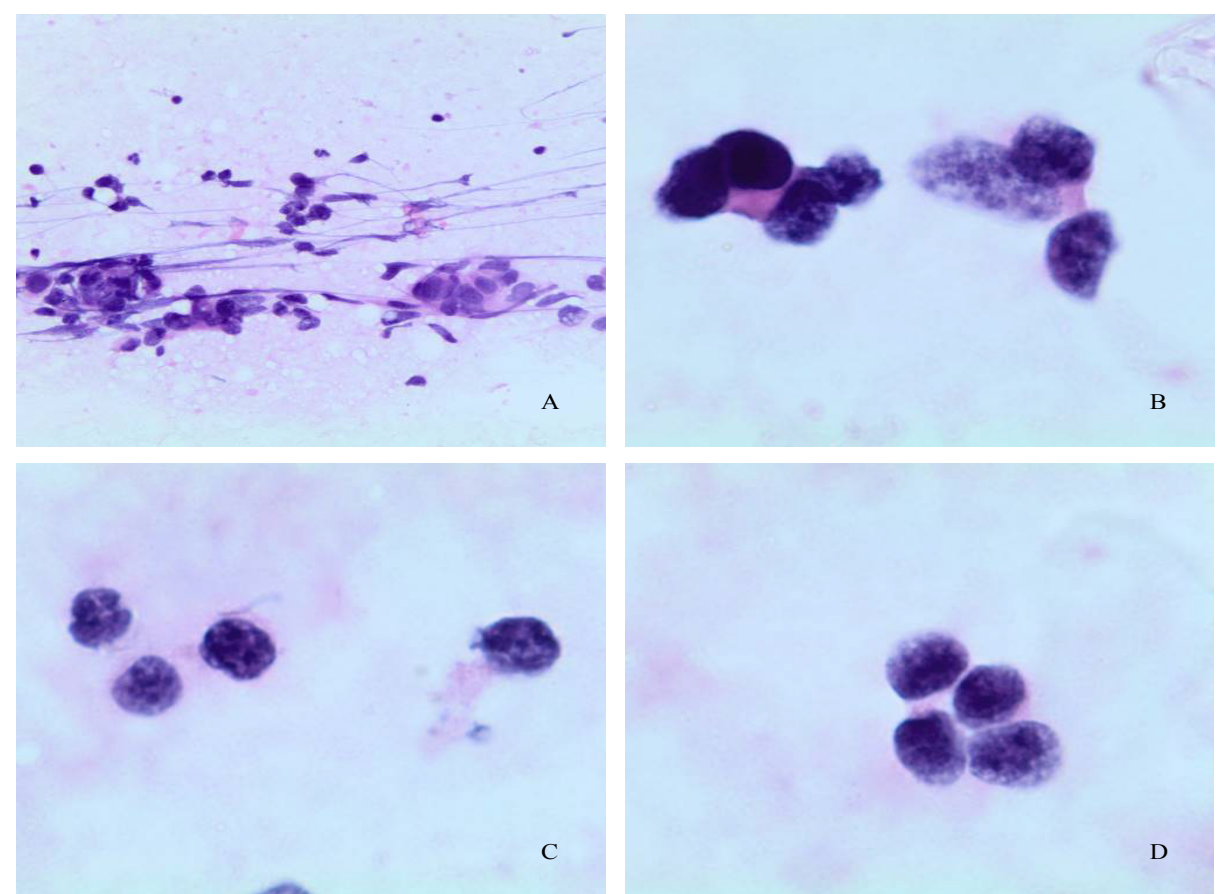

Figura 2: Examenul citopatologic al puncției tiroidiene - colorație Papanicolau. A) celularitate abundentă într-o metastază de tumoare neuroendocrină în tiroidă. B) celule cu nucleu mărit de volum și citoplasmă foarte puțină. Cromatină nucleară cu aspect granular. C, D) celule izolate, foarte discret pleomorfe, cu nuclei măriți de volum și cu aspect de tip endocrinoid al cromatinei nucleare.

diagnosticului. Metastazează preponderent pe cale hematogenă în plămânul controlateral, ficat, glande suprarenale, creier, oase, măduva osoasă $[2,3]$. Prezența metastazelor tiroidiene reprezintă este un semn de stadiu avansat de boală, adesea fiind asociate cu metastaze și în alte organe (rar evidențiabile clinic), pentru majoritatea pacienților decesul survenind în următoarele 9 luni de la diagnosticul acestora [2].

În combinație cu aspectul histologic, marker-ul de proliferare celulară Ki-67 pare să fie fie cel mai util marker de distincție între carcinoidele pulmonare (CT, CA) și formele cu grad înalt de malignitate (CNECm și respectiv CNECM). În determinarea diagnosticului diferențial o varietate de alți markeri tumorali pot fi de asemenea utili. Astfel, Cg A este exprimată $100 \%$ de carcinoidele pulmonare, $74 \%$ de varianta cu celule mari și 34\% de CNECm. SNF în 97\% de CT, $89 \%$ de CA, $65 \%$ de CNECM și $25 \%$ de CNECm. ENS este exprimată frecvent de toate carcinoidele (CT - 99\%, CA - 85\%, CNECM - 69\%, CNECm - 100\%). Serotonina este în mod obișnuit exprimată de CT și CA (67\%, respectiv 50\%) și rar de CNECm (11\%) [4].

Tumorile agresive pot determina apariția de noduli tiroidieni dureroși cu creștere rapidă, simptome de compresie locală și uneori tireotoxicoză de însoțire determinată de tiroidita de distrucție [5].
Creșterea lentă a TNE bine diferențiate poate fi responsibilă pentru absența simptomelor locale și a tireotoxicozei prin distrucție, metastazele tiroidiene fiind diagnosticate și la 2-3 ani după diagnosticul TNE primare. Perioada medie de latență raportată în literatura de specialitate, între diagnosticul tumorii primare și cel al metastazelor tiroidiene a fost de 9 luni [3]. În cazul pacientei prezentate în acest articol modul de prezentare și respectiv diagnosticul CNECm a fost prin metastazele la distanță localizate în tiroidă, trahee, limfonoduli cervicali (anterior și latero-cervical bilateral), supraclavicular, tumora primară fiind vizualizată imagistic la 6 luni de la diagnostic.

Dacă diagnosticul tumorii primare nu este evident, metastazele tiroidiene de carcinom neuroendocrin poate duce la confuzii de diagnostic. Leziunile tiroidiene metastatice de TNE pot mima carcinomul medular pe citologie sau pe examen histopatologic (EHP). Markerii imunohistochimici: $\mathrm{Cg}$ A, ENS și SNF sunt pozitivi atât pentru carcinomul medular tiroidian, cât și pentru TNE metastatice [6]. TNE metastatice ar trebui să fie imunohistochimic negative pentru calcitonină și ACE, în timp ce carcinomul medular tiroidian este pozitiv la acești markeri tumorali (la colorare) [6,7]. Uneori, imunocolorarea pentru calcitonină poate fi pozitivă în TNE. A fost raportat faptul că în special, varianta cu celule mici de carcinom tiroidian medular seamănă cu CNECm [8,9]. 
Într-un studiu radiologic efectuat pe 11 cazuri de CNECm s-a constatat că toți pacienții au prezentat leziuni cu aspect radiologic similar, caracterizat de mase centrale asociate cu adenopatii coalescente $\mathrm{cu}$ aspect heterogen și infiltrativ, cu invadarea structurilor vasculare şi a arborelui traheo-bronşic adiacent. Toate cazurile au prezentat și alte modificări toracice: leziuni pulmonare secundare, pneumonie, atelectazie, pleurezie și îngroșare pleurală. Pe radiografii caracterizarea maselor tumorale a fost în general mai dificilă, în special datorită prezenței atelectaziei și revărsatului pleural important. Metastaze la distanță au fost găsite la 10 pacienți (90\%) la momentul diagnosticului, mai ales în oase și abdomen superior (ficat și glande suprarenale), evidente de la prima evaluare computer tomografică toracică. Leziunile care au putut fi măsurate au fost mai mari de $5 \mathrm{~cm}$ în diametrul lor cel mai mare, unele dintre ele fiind mai mari de $10 \mathrm{~cm}$. Nu au fost identificate calcificări în nici o leziune. Toți pacienții au fost trimiși pentru tratament local sau sistemic cu evoluție progresivă nefavorabilă și deces în următoarele luni după confirmarea diagnosticului histopatologic [10].

Alegerea metodei de tratament depinde de: stadiul tumorii, tipul histologic, condiția clinică și biologică a pacientului. CNECm care nu este extins în afara cavității toracice are o rată de răspuns la combinația chimioterapie-radioterapie de $80-90 \%$. Pentru CNECm metoda de tratament de elecție este radio-chimioterapia, chirurgical interveninduse doar în cazuri selecționate de cancer localizat. Acest tip de cancer are o mare capacitate de diseminare, iar chirurgia nu îi poate opri evoluția $[11,12]$. Tratamentul cu analogi de somatostatină (Lanreotid, Octreotid) reprezintă un tratament pentru controlul simptomatologiei clinice produsă de secreţia aminelor biogene și pentru reducerea nivelului unor markeri hormonali; are efect limitat în reducerea volumului tumoral, și aceasta la tumorile bine/moderat diferenţiate, care prezintă receptori de somatostatin sensibili. Noi agenţi terapeutici (aflaţi în studii privind eficacitatea) includ radioterapia cu analogi radioactivi de somatostatină și chimioterapia cu inhibitori de receptori tirozin-kinazici. Tratamentul pentru TPNE avansate sau metastatice fiind în principal paleativ, trebuie să fie individualizat și presupune echipe multidisciplinare [13-15].

\section{Concluzii}

Este important de a considera existența posibilității metastazelor la pacienții cu noduli tiroidieni, și mai ales atunci când există istoric de tumoră malignă primară. Nodulii tiroidieni detectaţi în timpul monitorizării pacienților cu TNE trebuie investigați cu atenție. Puncția tiroidiană cu ac fin poate confirma diagnosticul, în cele mai multe cazuri și poate preveni abordări inutile de tratament.

\section{Conflict de interese}

Autorul nu declară nici un conflict de interese.

\section{Bibliografie}

1. Oberg K, Hellman P, Kwekkeboom D, Jelic S, ESMO Guidelines Working Group (2010) Neuroendocrine bronchial and thymic tumours: ESMO clinical practice guidelines for diagnosis, treatment and follow-up. Ann Oncol 21: v220-v222.

2. Lin JD, Weng HF, Ho YS (1998) Clinical and pathological characteristics of secondary thyroid cancer. Thyroid 8: 149-153.

3. Lam KY, Lo CY (1998) Metastatic tumors of the thyroid gland: a study of 79 cases in Chinese patients. Arch Pathol Lab Med 122: 37-41.

4. Gustafsson BI, Kidd M, Modlin IM (2007) Bronchopulmonary carcinoid tumors In: Modlin I, Oberg K, editors. A Century of Advances in Neuroendocrine Tumor Biology and Treatment. Hannover: Felsenstein CCCP.

5. Yamada H, Hasegawa Y, Mitsudomi T, Nakashima T, Yatabe Y (2007) Neuroendocrine tumor metastasis to the thyroid gland. Int J Clin Oncol 12: 63-67.

6. Maly A, Meir K, Maly B (2006) Isolated carcinoid tumor metastatic to the thyroid gland: report of a case initially diagnosed by fine needle aspiration cytology. Acta Cytol 50:84-87.

7. La Rosa S, Imperatori A, Giovanella L, Garancini S, Capella C (2009) Thyroid metastasis from typical carcinoid of the lung differentiating between medullary thyroid carcinoma an neuroendocrine tumor metastasis to the thyroid. Thyroid 19: $521-526$.

8. Yerli S, Triponez F, Meyer P, Kumar N, Bongiovanni M (2001) Medullary thyroid carcinoma, small cell variant as a diagnostic chal lenge on fine needle aspiration: a case report. Acta Cytol 54: 911-917.

9. Matias-Guiu X, LaGuette J, Puras-Gil AM, Rosai J (1997) Metastatic neuroendocrine tumor mimicking medullary carcinoma: a pathologic and immunohistochemical study of six cases. Am J Surg Pathol 21:754-762.

10. Santos MK, Barreto FAR, Chagas NFA, Muglia VF, Jorge E Jr (2012) Neuroendocrine tumors of the lung: major radiologic findings in a series of 22 histopathologically confirmed cases. Radiol Bras 45:191-197.

11. Katsenos S, Archondakis S, Vaias M, Skoulikaris N (2013) Thyroid gland metastasis from small cell lung cancer: an unusual site of metastatic spread. J Thorac Dis 5: E21-E24.

12. Beach DF, Klump WJ, Haddad G, Reid LM, Schwarting R, et al (2012) Extrapulmonary small cell: a novel case of small cell carcinoma of the thyroid gland. Med Oncol 29:1405-1408.

13. Travis WD (2010) Advances in neuroendocrine lung tumors. Ann Oncol 21 vii65-vii71.

14. Zhang $Y$, Jianxing $H(2013)$ The development of targeted therapy in small cell lung cancer. Thorac Dis 5: 538-548.

15. Eckhoff AF, Demes M (2012) Neuroendocrine Tumors of the Lung. Cancers (Basel) 4: 777-798. 